\title{
Penyalahgunaan Media Sosial Sebagai Alat Propaganda
}

\author{
Rety Palupi \\ Universitas Bina Sarana Informatika \\ e-mail: rety.ryp@bsi.ac.id
}
Cara Sitasi: Palupi, R. (2019). Penyalahgunaan Media Sosial Sebagai Alat Propaganda. Jurnal Komunikasi, 10(1), 69-76.

\begin{abstract}
Changes in the communication of information continue to occur along with the advancement of technology in the digital era. Nowadays everyone can work as a journalist even though he or she has never learned the basics of journalism. The public also frequently receive information or news that raise the eyebrows - ranging from disaster threats to information about the political world. The finding of this research is that often information that circulates in the hands of Warganet is a hoax and even hate speech, despite the government efforts to reduce the spread of hoax and hate speech. With this paper, the author aims at disclosing the propaganda elements in the hoax and hate speech in the social media as in the digital era the social media is the most vulnerable in spreading of hoax news and hate speech. By utilising qualitative content analysis, the author discusses five hoax news and hate speeches which are dissected using nine propaganda practices. The conclusion obtained by the author is that the hoax news and hate speech comprise of elements of exaggeration, rhetoric, recognition and influence on a variety of parties, as well as prejudices supplemented by emotions.
\end{abstract}

Keywords: social media, hoax, hate speech, propaganda

\section{PENDAHULUAN}

Perkembangan teknologi komunikasi dan informasi melaju dengan begitu pesat. Dimana kini orang perorang dapat menjadi jurnalis dan komentator amatiran. Alaupun tidak semuanya mendapatkan dasar ilmu di bidang tersebut. Siapa saja bisa merespon informasi yang tersebar dengan cepat. Bahkan menjadi seorang jurnalis fotografi yang mampu menyebarkan informasi ataupub berita yang diperkuat dengan dokumentasi gambar.

Jika terus terjadi seperti yang diceritakan diatas, tanpa berbanding lurus dengan ilmu yang dimiliki, tidak heran jika kini banyak bertebaran berita bohong (hoax) dan berita penebar kebencian (hate speech). Berdasarkan informasi dari Kepala Subdit IT dan Cyber Crime Direktorat Tindak Pidana Ekonomi Khusus Bareskrim Polri, Kombes Pol Himawan Bayu Aji mengatakan, kasus ujaran kebencian tahun 2016 menempati urutan pertama terbanyak diadukan setelah kasus penipuan online. (Nadia Kemala Novanita, 2017)

Dengan kemajuan informasi yang begitu cepat, public difasilitasi oleh teknologi yang dapat memperburuk keadaan. Berita hoax dan hate speech dapat begitu mudah tersebar dengan adanya media social seperti Facebook, Twitter, ataupun aplikasi mobile phone seperti WhatsApp, Line, dan sebagainya. Dimana pada mediamedia komunikasi dan informasi tersebut tidak dapat dilakukan filtrasi di awal.

Dampaknya adalah jika berita hoax dan hate speech tersebut jatuh dilihat oleh orang-orang yang mudah percaya, maka akan disebarkan kembali melalui media social ataupun messanger application yang dimilikinya. Dan hal ini akan terjadi terus menerus, dan berulang hingga banyaknya public yang terpengaruh dengan berita hoax dan hate speech. Dampak yang lebih besar adalah, memungkinkan adanya penggiringan opini yang dapat menyudutkan satu pihak atau menimbulkan kepanikan.

Sebagai contoh adalah, saat terjadi gempa bumi di wilayah Banten pada tanggal 23 Januari 2018, diikuti dengan adanya informasi gempa susulan lebih besar dan lebih berdampak berbahaya yang akan terjadi pada malam harinya. Hingga hal tersebut diklarifikasi sendiri oleh BMKG (Badan Meteorologi Klimatologi dan Geofisika) menyatakan informasi tersebut adalah bohong atau hoax. Dengan postingan resmi di akun media social twitternya, BMKG mengungkapkan : “\#BMKG tidak pernah mengeluarkan tentang prediksi \#gempa yang akan terjadi lengkap dengan waktu, tempat, dan besar magnitude-nya. Kami pastikan itu \#Hoax” (Atriana, 2018)

Krisis berita hoax dan hate speech juga masih banyak terjadi pada dunia politik. Diluar dari kepentingan politik apapun, hoax dan hate speech kini dapat dengan mudah kita temui. Seperti yang dilansir oleh 
CNN Indonesia menyebutkan bahwa dalam data yang dipaparkan oleh Kementerian Komunikasi dan Informatika menyebutkan ada sebanyak 800 ribu situs di Indonesia yang terindikasi sebagai penyebar berita palsu dan ujaran kebencian (Bintang Pratama, 2016). Dengan banyaknya hoax dan hate speech di dunia online, maka akan semakin meningkatnya propaganda yang terjadi. Mengapa demikian? Karena baik itu politik ataupun non politik yang memiliki kepentingan sendiri dan cenderung tidak menyukai keadaan yang saat ini terjadi. Dengan demikian propaganda dimaksudkan agar orang yang membacanya menjadi setuju dengan pemikiran dirinya. Berdasarkan krisis tersebut, baik hoax ataupun hate speech perlu kita ketahui ciri khasnya. Agar warganet mampu membendung propaganda tidak meluas. Maka dalam hal ini penulis ingin membedah beberapa pemberitaan yang telah dinyatakan hoax dan ataupun hate speech yang sempat tersebar. Dengan menggunakan analisis kualitatif dengan mencari ciri khasnya berdasarkan teknik-teknik propaganda menurut Dr. Joseph Gobbels, maka penulis akan membedah berita-berita hoax dan hate speech tersebut.

Dari pemaparan sebelumnya, didapatkan bahwa ada suatu fenomena pemberitaan hoax dan hate speech yang sudah cukup meluas. Hoax dan hate speech banyak tersebar melalui media social ataupun broadcast messanger yang dapat memberikan efek propaganda terhadap pembacanya. Menariknya media social yang dianggap paling berperan dalam penyebaran hoax dan hate speech. Karena Media sosial adalah sebuah media online, dengan para penggunanya bisa dengan mudah berpartisipasi, berbagi dan menciptakan isi.

Dengan demikian, menggunakan media sosial menjadikan kita sebagai diri sendiri. Selain kecepatan informasi yang bisa diakses dalam hitungan detik, menjadi diri sendiri dalam media sosial adalah alasan mengapa media sosial berkembang pesat. Tak terkecuali, keinginan untuk aktualisasi diri dan kebutuhan menciptakan personal branding. Teknologi-teknologi web baru memudahkan semua orang untuk membuat dan yang terpenting menyebarluaskan konten mereka sendiri. Post di Blog, tweet, atau video di YouTube dapat direproduksi dan dilihat oleh jutaan orang secara gratis.

Andreas Kaplan dan Michael Haenlein mendefinisikan media sosial sebagai "sebuah kelompok aplikasi berbasis internet yang membangun di atas dasar ideologi dan teknologi Web 2.0 , dan yang memungkinkan penciptaan dan pertukaran user-generated content". (Kaplan \& Haenlein, 2010). Selain itu Media sosial mempunyai ciri - ciri sebagai berikut:

a. Pesan yang disampaikan tidak hanya untuk satu orang saja namun bisa keberbagai banyak orang contohnya pesan melalui SMS ataupun internet.

b. Pesan yang disampaikan bebas, tanpa harus melalui suatu Gatekeeper.

c. Pesan yang disampaikan cenderung lebih cepat di banding media lainnya.

d. Penerima pesan yang menentukan waktu interaksi.

Media sosial yang berbasis pada teknologi juga mengambil berbagai bentuk termasuk majalah, forum internet, webblog, blog sosial, microblogging, wiki, podcast, foto atau gambar, video, peringkat dan bookmark sosial. Dengan menerapkan satu set teoriteori dalam bidang media penelitian (kehadiran sosial, media kekayaan) dan proses sosial (selfpresentasi, self-disclosure) Kaplan dan Haenlein menciptakan skema klasifikasi untuk berbagai jenis media social dalam artikel Horizons Bisnis mereka diterbitkan dalam 2010. (Kaplan \& Haenlein, 2010) Masih menurut Kaplan dan Haenlein ada enam jenis media sosial:

a. Proyek Kolaborasi

Website mengizinkan usernya untuk dapat mengubah, menambah, ataupun me-remove konten-konten yang ada di website ini.Contohnya wikipedia.

b. Blog dan microblog

User lebih bebas dalam mengekspresikan sesuatu di blog ini seperti curhat ataupun mengkritik kebijakan pemerintah. Contohnya Twitter, Blogspot, Tumblr, Path dan lain-lain.

c. Konten

Para user dari pengguna website ini saling mengshare konten - konten media, baik seperti video, ebook, gambar dan lain-lain. Contohnya Youtube.

d. Situs jejaring sosial

Aplikasi yang mengizinkan user untuk dapat terhubung dengan cara membuat informasi pribadi sehingga dapat terhubung dengan orang lain. Informasi pribadi itu bisa seperti foto-foto. Contoh Facebook, Path, Instagram dan lain-lain. 5.

e. Virtual game world

Dunia virtual dimana mereplikasikan lingkungan 3D, di mana user bisa muncul dalam bentuk avatar-avatar yang diinginkan serta berinteraksi dengan orang lain selayaknya di dunia nyata, contohnya game online.

f. Virtual social world.

Dunia virtual yang di mana penggunanya merasa hidup di dunia virtual, sama seperti virtual game world, berinteraksi dengan yang lain. Namun, Virtual Social World lebih bebas, dan lebih ke arah kehidupan, contohnya second life.

Sebuah pertanyaan besar muncul mengenai bagaimana cara kita mengetaui berita tersebut merupakan hoax atau hate speech yang menuju pada 
propaganda? Tulisan ini diharapkan dapat menjadi acuan bagi warganet untuk mengetahui pemberitaan mana yang mengandung propaganda karena didalamnya terdapat informasi hoax ataupun hate speech.

\section{METODOLOGI PENELITIAN}

Penyusunan karya tulis ini menggunakan pendekatan kualitatif dengan sifat pendekatan deskriptif. Kualitatif dipilih karena "Data dikumpulkan bukan dalam bentuk angka namun dalam bentuk wawancara, studi dokumen, catatan, dan observasia pengamatan. Sehingga melalui pendekatan ini bisa menjelaskan fenomena yang terjadi secara mendalam. Oleh karena itu penggunaan metode kualitatif dalam penelitian ini untuk membandingkan realita yang ada dengan teori yang berkaitan” (Jiwarka \& Subagyo, 2014).

Jenis penelitian yang dipakai penulis dalam tulisan ilmiah ini adalah analisis isi. Altheide pada tahun 1996 mengatakan bahwa analisis isi kualitatif disebut pula sebagai Ethnographic Content Analysis (ECA), yaitu perpaduan analisis objektif dengan observasi partisipan. Artinya, istilah ECA adalah periset berinteraksi dengan material-material dokumentasi atau bahkan melakukan waancara mendalam sehingga pernyataan-pernyataan yang spesifik dapat diletakkan pada konteks yang tepa untuk dianalisis. Disini penulis melakukan pembedahan beberapa media yang telah dinyatakan hoax dan atau hate speech dan memberikan berita tersebut kepada beberapa orang narasumber dengan background yang berbeda untuk memberikan kesannya setelah membaca berita tersebut.

Ida dalam Kriantono (Kriyantono, 2009) memaparkan beberapa hal yang perlu diperhatikan oleh periset dalam melakukan analisis isi kualitatif adalah :

1. Isi (content) atau situasi sosial seputar dokumen (pesan/teks) yang diriset

2. Proses atau bagaimana suatu produk media/isi pesannya dikreasi secara aktual dan diorganisasikan secara bersama.

3. Emergence, yakni pembentukan secara gradual/bertahap dari makna sebuah pesan melalui pemahaman dan interpretasi.

Analisis isi kemudian dibedah berdasarkan teori propaganda. Dalam kamus Besar Bahasa Indonesia, atau dalam arti etimologis, propaganda berarti penerangan, paham, sikap, atau arah tindakan tertentu, biasanya disertai dengan janji muluk-muluk. Lasswell dalam Cangara mengartikan Propaganda sebagai proses diseminasi informasi untuk mempengaruhi sikap dan tingkah laku seseorang atau kelompok masyarakat dengan notif indoktrinasi ideologi. Teori ini mengadaptasi teori freudianisme dan teori behaviorisme, puncak implementasinya untuk mencapai efek dukungan massa. Teori ini tersublimasi dalam rumusan paradigma komunikasi yang terkenal (who says what to whom in which channel with what effect). (Cangara, 2014).

Cangara mengungkapkan dalam bukunya bahwa propaganda rawan terhadap praktik-praktik penipuan yang biasa dilakukan melalui propaganda yang perlu diwaspadai seseorang, antara lain:

1. Memberi julukan (name calling)

Cara ini digunakan untik menjelek-jelekan seseorang dengan memberi gelaran yang lucu atau sinis sehingga orang yang dipengaruhi benar-benar yakin.

2. Gemerlap (glittering generalities)

Propaganda yang menggunakan kata-kata bombastis sehingga orang tanpa sadar mengikutinya.

3. Pengalihan (transfer)

Teknik propaganda yang dilakukan dengan cara pengalihan pada objek lain.

4. Pengakuan (testimonial)

Teknik pengakuan dengan menggunakan namanama orang terkenal seperti bintang film dan olahragawan, meskipun sebenarnya yang bersangkutan tidak memakainya.

5. Flain Folks

Teknik yang sering dipakai politisi untuk mempengaruhi orang banyak. Contohnya seperti, walaupun tokoh tersebut sudah menjadi orang penting, namun tetap bermasyarakat seperti orang-orang pada umumnya.

6. Pengikut (bandwagon)

Teknik ini ditujukan kepada orang-orang yang berpengaruh seperti kepala kantor, pemimpin partai, kepala desa, dan lain sebagainya.

7. Memakai fakta (card stacking)

Digunakan untuk mencoba mengemukakan fakta untuk meyakinkan orang lain.

8. Kecurigaan yang penuh emosi (emotional stereotype)

Teknik propaganda untuk menumbuhkan rasa curiga yang penuh emosi.

9. Retorika

Teknik yang dibunakan dengan memilih katakata yang bisa menarik seseorang sehingga orang itu bisa menuriti kehendaknya.

Dari ke 9 poin diatas, penulis akan membahas isi informasi yang telah diklarifikasi sebagai berita hoax atau hate speech.

\section{HASIL DAN PEMBAHASAN}

Penulis telah mengumpulkan 5 (lima) berita yang telah diklarifikasi sebagai berita hoax atau hate speech yang memungkinkan didalamnya terdapat hal yang dapat memberikan efek propaganda.

1. Pesan berantai sesaat setelah terjadinya gempa Banten : Diharap keluar rumah nanti malam pukul 22.30-23.59 dikarenakan potensi gempa 
susulan sebesar 7,5 SR Magnitude. Bagi yang tahu harap sebarkan berita penting ini.

2. Pesan berantai ketika gunung kelud sedang aktif : Info dari BMG 2 jam lagi ada letusan susulan status AWAS II ,diperkirakan letusan sejauh 20 $\mathrm{km}$ dari pusat magma dan diperkirakan terjadi gempa 6 sampai 8 skalalighter. Dan setelah ini lampu akan dipadamkan total untuk wilayah kediri . .Lahar dingin mengalir sampai Kademangan Blitar hati2 untuk daerah alirah lahar,hujan abu dan suara gelegar letusan sampe solo dan klaten,sedangkan daerah kota pare kediri ke utara di selimuti bau belerang yg menyengat. Tolong sebarkan kabar ini ke sanak keluarga anda.Info : http//www.BMKG.co.id

3. Pesan berantai ketika ramainya berita tentang pembegalan : Bantu bc aja. Mohon perhatian sebentar!

Hati2 utk Wilayah seluruh negara indonesian. Pihak kepolisian akan melakukan Razia besar2an di semua titik. Razia dilakukn dengan gabungan mulai dari Mabes, Polda, Polres hingga Polsek. Karena banyak kerabat para Pembegal atau Genk motor yang akan membalas dendam dikarenakan rekan2 mereka banyak yg tertangkap \& ada juga yang dibakar. Mereka berkata: "bahwasannya kami para pembegal motor akan membalas dendam atas perlakuan masyarakat yang main bakar terhadap angota kami, bahkan akan lebih kejam \& brutal di jalanan". Mereka berjanji setiap ada pengendara sepeda motor di pagi sd malam \& dini hari akan dibacok dan dicincang. Tlg sebarkn informasi ini bhw mulai jam 10 malam besok sampai dengan dini hari, penduduk dilarang beraktifitas keluar rumah disebabkn adanya teror balas-dendam dr komplotan pembegal dan Genk motor. Tadi siang kantor Polsek dilempari kertas yang bertulisan, "Nyawa harus dibayar dengan Nyawa dan kami akan bertumbuh menjadi besar," Para warga dihimbau JANGAN keluar pada mlm \& dini hari utk sementara, jika TIDAK ada hal-hal yang mendesak. Demikian pesan dr Humas MabesPolri. Bantu Share yaa .. demi keselamatan kwn2 \& keluarga kita. Tks.

4. Twit Ahmad Dhani di twitter pribadi miliknya saat momen Pilkada DKI Jakarta : Siapa saja yg dukung Penista Agama adalah Bajingan yg perlu di ludahi muka nya - ADP

5. Dugaan ujaran kebencian di ceramah Zulkifli Muhammad Ali : Kita mengikuti bagaimana perkembangan tahun 2018, ancaman kehancuran ekonomi global dan itu menyebabkan dimana-mana terjadi krisis, chaos, keributan, kekacauan, dan perang dimana-mana, termasuk Jakarta. Jakarta bapak dengar bagaimana revolusi yang dikhawatirkan para TNI, kita yang masih punya loyalitas kepada NKRI ini, revolusi Cina, maaf, revolusi komunis berkolaborasi dengan revolusi Syiah akan menjadikan Jakarta sebagai negeri terpanas yang penuh tumpahan darah. Apabila kita tidak bersiap-siap, maka umat tidak mau bersatu maka kita akan disembelih seperti saudara kita yang disembelih di Syria. Seperti saudara kita yang disembelih di Irak, sudara kita disembelih di Yaman, ini pasti terjadi kaum muslimin yang kami muliakan. Dan ini bukan suatu hal yang sangat tabu lagi. Jutaan KTP sedang dibuat sekarang di Cina, jutaan KTP dibuat sekarang di Paris, atas nama penduduk Indonesia.

Berdasarkan lima berita hoax atau hate speech diatas, penulis akan membahas menggunakan Sembilan praktik yang memungkinkan terjadinya propaganda.

\section{Memberi julukan (name calling)}

Cara ini digunakan untuk menjelek-jelekan seseorang dengan memberi gelaran yang lucu atau sinis sehingga orang yang dipengaruhi benar-benar yakin. Misalnya : dia itu cerdik seperti Abu Nawa, dia berperilaku sama seperti Yahudi, dan sebagainya. Maka dalam membahas lima berita hoax dan hate speech diatas, penulis telah merangkumnya sebagai berikut:

Tabel 1 : Praktik propaganda dengan memberi julukan

\begin{tabular}{clll}
\hline Berita & \multicolumn{3}{l}{ Analisa Memberi Julukan } \\
\hline Berita 1 & $\begin{array}{l}\text { Tidak ada isi pesan } \\
\text { menjelekkan 1 pihak }\end{array}$ & yang \\
\hline Berita 2 & $\begin{array}{l}\text { Tidak ada isi pesan } \\
\text { menjelekkan 1 pihak }\end{array}$ & yang \\
\hline Berita 3 & $\begin{array}{l}\text { Tidak ada isi pesan } \\
\text { menjelekkan 1 pihak }\end{array}$ & yang \\
\hline Berita 4 & $\begin{array}{l}\text { Isi pesan terdapat } \\
\text { menjelekkan 1 pihak }\end{array}$ & yang \\
\hline Berita 5 & $\begin{array}{l}\text { Isi pesan terdapat } \\
\text { menjelekkan 1 pihak }\end{array}$ & yang \\
\end{tabular}

Berdasasarkan 5 (lima) berita yang mengandung hoax atau hate speech, maka ditemukan 2 (dua) dari 5 (lima) berita diatas mengandung unsur menjelekjelekan salah satu pihak. Dan jika penulis beri kesimpulan, kedua berita yang menjelekan satu pihak merupakan unsur berita hate speech.

\section{Gemerlap (glittering generalities)}

Pada poin ini penulis mencoba memetakan propaganda pada ke-lima berita diatas yang menggunakan kata-kata bombastis sehingga orang tanpa sadar mengikutinya. Contohnya : barangnya sudah habis, tapi masih banyak yang mau. Atau, mohon maaf kepada warga Jakarta atas kemacetan lalulintas karena simpatisan partai $\mathrm{X}$ yang telah membludak. Karen ajika kita telaan lebih jauh, tanpa adanya simpatisan partai $\mathrm{X}$, Jakarta memang sering 
macet. Maka dalam membahas lima berita hoax dan hate speech diatas, penulis telah merangkumnya sebagai berikut:

Tabel 2 : Praktik propaganda dengan praktik poin gemerlap

\begin{tabular}{|c|c|}
\hline Berita & Analisa Poin Gemerlap \\
\hline Berita 1 & $\begin{array}{l}\text { Isi pesan terdapat hal yang bernilai } \\
\text { bombastis pada kalimat "potensi } \\
\text { gempa susulan sebesar } 7,5 \text { SR" }\end{array}$ \\
\hline Berita 2 & $\begin{array}{l}\text { Isi pesan terdapat hal yang bernilai } \\
\text { bombastis pada sepanjang } \\
\text { kalimatnya }\end{array}$ \\
\hline Berita 3 & $\begin{array}{l}\text { Isi pesan terdapat hal yang bernilai } \\
\text { bombastis pada sepanjang } \\
\text { kalimatnya }\end{array}$ \\
\hline Berita 4 & $\begin{array}{l}\text { Isi pesan terdapat hal yang bernilai } \\
\text { bombastis pada kalimat "Bajingan } \\
\text { yg perlu di ludahi muka nya" }\end{array}$ \\
\hline Berita 5 & $\begin{array}{l}\text { Isi pesan terdapat hal yang bernilai } \\
\text { bombastis pada kalimat "Jakarta } \\
\text { sebagai negeri terpanas yang } \\
\text { penuh tumpahan darah, seperti } \\
\text { saudara kita yang disembelih di } \\
\text { Syria" }\end{array}$ \\
\hline
\end{tabular}

Berdasasarkan 5 (lima) berita yang mengandung hoax atau hate speech, maka ditemukan pada seluruh berita tersebut mengandung unsur melebih-lebihkan, membesar-besarkan, atau nilai bombastis. Baik itu merupakan berita hoax ataupun hate speech tetap memasukan praktik propaganda membesarkan isi pesan.

\section{Pengalihan (transfer)}

Pada bahasan mengenai praktik propaganda menggunakan pengalihan penulis mencoba menganalisa yang dilakukan praktik propaganda dengan cara pengalihan pada objek lain pada kelima berita diatas.

Tabel 3 : praktik propaganda dengan praktik pengalihan

\begin{tabular}{cl}
\hline Berita & Analisa Praktik Pengalihan \\
\hline Berita 1 & $\begin{array}{l}\text { Isi pesan tidak terdapat hal yang } \\
\text { bernilai pengalihan pada hal lain }\end{array}$ \\
\hline Berita 2 & $\begin{array}{l}\text { Isi pesan tidak terdapat hal yang } \\
\text { bernilai pengalihan pada hal lain }\end{array}$ \\
\hline Berita 3 & $\begin{array}{l}\text { Isi pesan tidak terdapat hal yang } \\
\text { bernilai pengalihan pada hal lain }\end{array}$ \\
\hline Berita 4 & $\begin{array}{l}\text { Isi pesan tidak terdapat hal yang } \\
\text { bernilai pengalihan pada hal lain }\end{array}$ \\
\hline Berita 5 & $\begin{array}{l}\text { Isi pesan tidak terdapat hal yang } \\
\text { bernilai pengalihan pada hal lain }\end{array}$ \\
\hline
\end{tabular}

Berdasasarkan 5 (lima) berita yang mengandung hoax atau hate speech diatas, maka ditemukan pada seluruh berita tersebut tidak mengandung unsur pengalihan pada objek lain. Baik itu merupakan berita hoax ataupun hate speech tetap tidak ditemukan praktik pengalihan pada isi pesan.

\section{Pengakuan (testimonial)}

Penulis mencoba mencari teknik pengakuan dengan menggunakan nama-nama orang terkenal seperti bintang film dan olahragawan dalam kelima berita diatas. Meskipun sebenarnya yang bersangkutan tidak memakainya.

Tabel 4 : praktik propaganda dengan praktik pengakuan

\begin{tabular}{cl}
\hline Berita & Analisa Praktik Pengakuan \\
\hline Berita 1 & $\begin{array}{l}\text { Isi pesan terdapat hal yang bernilai } \\
\text { pengakuan dengan menyertakan } \\
\text { nama BMKG }\end{array}$ \\
\hline Berita 2 & $\begin{array}{l}\text { Isi pesan terdapat hal yang bernilai } \\
\text { pengakuan dengan menyertakan } \\
\text { nama BMKG }\end{array}$ \\
\hline Berita 3 & $\begin{array}{l}\text { Isi pesan terdapat hal yang bernilai } \\
\text { pengakuan dengan menyertakan } \\
\text { nama pihak kepolisian }\end{array}$ \\
\hline Berita 4 & $\begin{array}{l}\text { Isi pesan tidak terdapat hal yang } \\
\text { bernilai pengakuan }\end{array}$ \\
\hline Berita 5 & $\begin{array}{l}\text { Isi pesan tidak terdapat hal yang } \\
\text { bernilai pengakuan }\end{array}$ \\
\hline
\end{tabular}

Berdasasarkan 5 (lima) berita yang mengandung hoax atau hate speech, maka ditemukan 3 (tiga) berita diatas mengandung unsur pengakuan dari pihak tertentu. Dan jika penulis beri kesimpulan, ketiga berita yang membawa nama pihak lain tersebut merupakan berita hoax yang ingin meningkatkan kepanikan pada public.

\section{Flain Folks}

Pada poin ini penulis mencoba menemukan Teknik yang sering dipakai politisi untuk mempengaruhi orang banyak di lima berita hoax dan hate speech diatas. Contohnya seperti, walaupun tokoh tersebut sudah menjadi orang penting, namun tetap bermasyarakat seperti orang-orang pada umumnya.

Tabel 5 : praktik propaganda dengan praktik Flain Folks

\begin{tabular}{|c|c|}
\hline Berita & Analisa Praktik Flain Folks \\
\hline Berita 1 & $\begin{array}{l}\text { Isi pesan terdapat hal yang ingin } \\
\text { mempengaruhi orang lain dengan } \\
\text { menganjurkan keluar malam pada } \\
\text { waktu tertentu. }\end{array}$ \\
\hline Berita 2 & $\begin{array}{l}\text { Isi pesan terdapat hal yang ingin } \\
\text { mempengaruhi orang lain dengan } \\
\text { menganjurkan menyebarkan info } \\
\text { tersebut kepada pihak lain }\end{array}$ \\
\hline Berita 3 & $\begin{array}{l}\text { Isi pesan terdapat hal yang ingin } \\
\text { mempengaruhi orang lain dengan }\end{array}$ \\
\hline
\end{tabular}




\begin{tabular}{cl}
\hline & $\begin{array}{l}\text { menganjurkan menyebarkan info } \\
\text { tersebut kepada pihak lain }\end{array}$ \\
\hline Berita 4 & $\begin{array}{l}\text { Isi pesan tidak terdapat hal yang } \\
\text { ingin mempengaruhi orang lain }\end{array}$ \\
\hline Berita 5 & $\begin{array}{l}\text { Isi pesan tidak terdapat hal yang } \\
\text { ingin mempengaruhi orang lain }\end{array}$ \\
\hline
\end{tabular}

Berdasasarkan 5 (lima) berita yang mengandung hoax atau hate speech, maka ditemukan 3 (tiga) berita diatas mengandung unsur untuk mempengaruhi pihak tertentu. Dan jika penulis beri kesimpulan, ketiga berita yang mempengaruhi pihak lain yang membacanya merupakan berita hoax yang ingin meningkatkan kepanikan pada public.

\section{Pengikut (bandwagon)}

Pada poin ini penulis coba temukan apakah isi berita tersebut memiliki tujuan kepada orangorang yang berpengaruh seperti kepala kantor, pemimpin partai, kepala desa, dan lain sebagainya.

Tabel 6 : praktik propaganda dengan praktik pengikut

\begin{tabular}{cl}
\hline Berita & Analisa Praktik Pengikut \\
\hline Berita 1 & $\begin{array}{l}\text { Isi pesan tidak ditujukan kepada } \\
\text { orang-orang yang berpengaruh. }\end{array}$ \\
\hline Berita 2 & $\begin{array}{l}\text { Isi pesan tidak ditujukan kepada } \\
\text { orang-orang yang berpengaruh }\end{array}$ \\
\hline Berita 3 & $\begin{array}{l}\text { Isi pesan tidak ditujukan kepada } \\
\text { orang-orang yang berpengaruh. }\end{array}$ \\
\hline Berita 4 & $\begin{array}{l}\text { Isi pesan tidak ditujukan kepada } \\
\text { orang-orang yang berpengaruh. }\end{array}$ \\
\hline Berita 5 & $\begin{array}{l}\text { Isi pesan tidak ditujukan kepada } \\
\text { orang-orang yang berpengaruh. }\end{array}$ \\
\hline
\end{tabular}

Berdasasarkan 5 (lima) berita yang mengandung hoax atau hate speech diatas, maka ditemukan pada seluruh berita tersebut tidak mengandung isi yang ditujukan khusus kepada pemimpin atau orang yang berpengaruh. Baik itu merupakan berita hoax ataupun hate speech tetap tidak ditemukan praktik tujuan kepada pimpinan. Semua berita ditujukan untuk warganet yang membaca.

\section{Memakai fakta (card stacking)}

Penulis mencoba menmanfaatkan poin ini untuk menemukan isi berita tersebut apakah digunakan untuk mencoba mengemukakan fakta untuk meyakinkan orang lain. Misalnya, dibalik berita itu, ia menutupi kekurangan yang dimilikinya.

Tabel 7 : praktik propaganda dengan praktik memaknai fakta

\begin{tabular}{ll}
\hline Berita & $\begin{array}{l}\text { Analisa } \\
\text { Fakta }\end{array}$ \\
\hline Berita 1 & $\begin{array}{l}\text { Isi pesan tidak berisi ungkapan } \\
\text { fakta untuk menutupi kekurangan } \\
\text { pribadi }\end{array}$ \\
\hline
\end{tabular}

\begin{tabular}{|c|c|}
\hline Berita 2 & $\begin{array}{l}\text { Isi pesan tidak berisi ungkapan } \\
\text { fakta untuk menutupi kekurangan } \\
\text { pribadi }\end{array}$ \\
\hline Berita 3 & $\begin{array}{l}\text { Isi pesan tidak berisi ungkapan } \\
\text { fakta untuk menutupi kekurangan } \\
\text { pribadi }\end{array}$ \\
\hline Berita 4 & $\begin{array}{l}\text { Isi pesan berisi ungkapan fakta } \\
\text { untuk menutupi kekurangan } \\
\text { pribadi dengan kata-kata yang } \\
\text { cenderung kasar. }\end{array}$ \\
\hline Berita 5 & $\begin{array}{l}\text { Isi pesan berisi ungkapan fakta } \\
\text { untuk menutupi kekurangan } \\
\text { pribadi yaitu ketakutan dari } \\
\text { ancama-ancaman }\end{array}$ \\
\hline
\end{tabular}

Berdasasarkan 5 (lima) berita yang mengandung hoax atau hate speech, maka ditemukan 2 (dua) dari 5 (lima) berita diatas mengandung unsur menutupi kekurangan sendiri yang dimilikinya. Dan jika penulis beri kesimpulan, kedua berita yang termasuk dalam praktik ini merupakan unsur berita hate speech.

\section{Kecurigaan yang penuh emosi (emotional stereotype)}

Penulis ingin menemukan Teknik propaganda yang bertujuan untuk menumbuhkan rasa curiga yang penuh emosi pada kelima berita diatas. Misalnya memberi penanaman kepercayaan yang bersifat negative karena stereotip seperti etnis, agama, dan keturunan.

Tabel 8 : praktik propaganda dengan praktik curiga dan emosi

\begin{tabular}{cl}
\hline Berita & \multicolumn{2}{c}{$\begin{array}{c}\text { Analisa Praktik Curiga dan } \\
\text { Emosi }\end{array}$} \\
\hline Berita 1 & $\begin{array}{l}\text { Isi pesan tidak berisi ungkapan } \\
\text { kecurigaan yang penuh emosi }\end{array}$ \\
\hline Berita 2 & $\begin{array}{l}\text { Isi pesan tidak berisi ungkapan } \\
\text { kecurigaan yang penuh emosi. }\end{array}$ \\
& Hanya terdapat pesan ancaman \\
& bencana. \\
\hline Berita 3 & $\begin{array}{l}\text { Isi pesan berisi ungkapan } \\
\text { kecurigaan yang penuh emosi } \\
\\
\text { ketakutan akan pembegalan }\end{array}$ \\
\hline Berita 4 & $\begin{array}{l}\text { Isi pesan berisi ungkapan } \\
\text { kecurigaan yang penuh emosi } \\
\text { dengan ancaman penganalogian }\end{array}$ \\
\hline Berita 5 & $\begin{array}{l}\text { Isi pesan berisi ungkapan } \\
\text { kecurigaan yang penuh emosi di } \\
\text { sepanjang isi berita }\end{array}$ \\
\hline
\end{tabular}

Berdasasarkan 5 (lima) berita yang mengandung hoax atau hate speech, maka ditemukan 3 (tiga) berita diatas mengandung unsur kecurigaan yang penuh emosi. Dan jika penulis beri kesimpulan, ketiga berita yang menimbulkan kecurigaan dan emosi, berasal dari dua berita hate speech dan satu berita hoax. 


\section{Retorika}

Pada poin ke Sembilan ini, penulis mencoba menemukan adakah teknik yang digunakan pada kelima berita diatas dengan memilih kata-kata yang bisa menarik seseorang sehingga orang itu bisa menuruti kehendaknya.

Tabel 9 : praktik propaganda dengan Praktik Retorika

\begin{tabular}{|c|c|}
\hline Berita & Analisa Praktik Retorika \\
\hline Berita 1 & $\begin{array}{l}\text { Isi pesan berisi ungkapan retorika } \\
\text { yang mempengaruhi orang lain } \\
\text { untuk menyebarkan berita karena } \\
\text { informasi bencana yang besar }\end{array}$ \\
\hline Berita 2 & $\begin{array}{l}\text { Isi pesan berisi ungkapan retorika } \\
\text { yang mempengaruhi orang lain } \\
\text { untuk menyebarkan berita karena } \\
\text { informasi letusan gunung yang } \\
\text { akan berdampak luas }\end{array}$ \\
\hline Berita 3 & $\begin{array}{l}\text { Isi pesan berisi ungkapan retorika } \\
\text { yang mempengaruhi orang lain } \\
\text { untuk menyebarkan berita karena } \\
\text { ancaman nyawa dari pembegalan }\end{array}$ \\
\hline Berita 4 & $\begin{array}{l}\text { Isi pesan berisi ungkapan retorika } \\
\text { yang mempengaruhi orang lain } \\
\text { untuk berbuat tidak sopan dalam } \\
\text { upaya membalas perilaku tertentu }\end{array}$ \\
\hline Berita 5 & $\begin{array}{l}\text { Isi pesan berisi ungkapan retorika } \\
\text { yang mempengaruhi orang lain } \\
\text { untuk melawan pihak-pihak } \\
\text { tertentu. }\end{array}$ \\
\hline
\end{tabular}

Berdasasarkan 5 (lima) berita yang mengandung hoax atau hate speech, maka ditemukan pada seluruh berita tersebut mengandung unsur retorika agar warganet yang membacanya terpangaruh dengan kata-kata yang disajikan. Baik itu merupakan berita hoax ataupun hate speech tetap memasukan praktik retorika pada isi beritanya

\section{KESIMPULAN}

Berdasarkan hasil pengamatan diatas berdasarkan 9 (sembilan) point utama maka dapat penulis simpulkan sebagai berikut:

1. Berdasasarkan 5 (lima) berita yang mengandung hoax atau hate speech, maka ditemukan 2 (dua) dari 5 (lima) berita diatas mengandung unsur menjelek-jelekan salah satu pihak.

2. Berdasasarkan 5 (lima) berita yang mengandung hoax atau hate speech, maka ditemukan pada seluruh berita tersebut mengandung unsur melebih-lebihkan, membesar-besarkan, atau nilai bombastis.

3. Berdasasarkan 5 (lima) berita yang mengandung hoax atau hate speech diatas, maka ditemukan pada seluruh berita tersebut tidak mengandung unsur pengalihan pada objek lain.
4. Berdasasarkan 5 (lima) berita yang mengandung hoax atau hate speech, maka ditemukan 3 (tiga) berita diatas mengandung unsur pengakuan dari pihak tertentu.

5. Berdasasarkan 5 (lima) berita yang mengandung hoax atau hate speech, maka ditemukan 3 (tiga) berita diatas mengandung unsur untuk mempengaruhi pihak tertentu.

6. Berdasasarkan 5 (lima) berita yang mengandung hoax atau hate speech diatas, maka ditemukan pada seluruh berita tersebut tidak mengandung unsur yang ditujukan khusus kepada pemimpin atau orang yang berpengaruh.

7. Berdasasarkan 5 (lima) berita yang mengandung hoax atau hate speech, maka ditemukan 2 (dua) dari 5 (lima) berita diatas mengandung unsur menutupi kekurangan sendiri yang dimilikinya.

8. Berdasasarkan 5 (lima) berita yang mengandung hoax atau hate speech, maka ditemukan 3 (tiga) berita diatas mengandung unsur kecurigaan yang penuh emosi.

9. Berdasasarkan 5 (lima) berita yang mengandung hoax atau hate speech, maka ditemukan pada seluruh berita tersebut mengandung unsur retorika agar warganet yang membacanya terpangaruh dengan katakata yang disajikan.

Dari ke 9 (sembilan) point tersebut dapat disimpulkan Untuk berita hoax ataupun hate speech lebih utama mengandung unsur melebih-lebihkan, retorika, pengakuan dan mempengaruhi pihak tertentu, serta kecurigaan yang disertai emosi.

Dengan hasil kesimpulan yang didapat diatas, maka pihak-pihak yang berkepentingan seperti kepolisian, kejaksaan, kementerian yang terkait dapat menggunakan parameter tersebut untuk menentukan proses tindak lanjutnya terhadap dalam upaya menekan penyebaran berita hoax dan hate speech

\section{DAFTAR REFERENSI}

Atriana, R. (2018). Beredar Kabar Ada Gempa Susulan 7,4 SR Nanti Malam, BMKG: Hoax. Retrieved from https://news.detik.com/berita/3829827/beredar -kabar-ada-gempa-susulan-nanti-malambmkg-pastikan-hoax

Bintang Pratama, A. (2016). Ada 800 Ribu Situs Penyebar Hoax di Indonesia. Retrieved from https://www.cnnindonesia.com/teknologi/2016 1229170130-185-182956/ada-800-ribu-situspenyebar-hoax-di-indonesia

Cangara, H. (2014). Komunikasi Politik: Konsep, Teori, dan Strategi (2014th ed.). Depok: Rajawali Pers.

Jiwarka, N. P. S., \& Subagyo. (2014). 
KEBERPIHAKAN MEDIA MASSA (Studi Kualitatif Analisis Framing Konflik Nasdem antara Hary Tanoe dan. Jurnal Komunikasi Massa, $1 . \quad$ Retrieved from http://www.jurnalkommas.com/docs/Jurnal KEBERPIHAKKAN MEDIA MASSA Novrian Panji (D0209062) - FISIP UNS.pdf

Kaplan, A. M., \& Haenlein, M. (2010). Users of the world, unite! The challenges and opportunities of Social Media. Business Horizons, 53, 59-68. https://doi.org/10.1016/j.bushor.2009.09.003

Kriyantono, R. (2009). Teknik Praktis Riset Komunikasi: Disertai Contoh Praktis Riset Media, Public Relations, Advertising, Komunikasi Organisasi, Komunikasi Pemasaran. Prenada Media Group.

Nadia Kemala Novanita, A. (2017). 2016, Konten
Berisi Ujaran Kebencian Paling Banyak Diadukan ke Polisi. Retrieved from https://nasional.kompas.com/read/2017/03/26/ 08465611/2016.konten.berisi.ujaran.kebencian .paling.banyak.diadukan.ke.polisi

\section{PROFIL PENULIS}

Rety Palupi, M.I.Kom. Lahir di Jakarta, 6 Maret 1988. Tahun 2013 lulus dari Program Strata 1 (S1) dari Fakultas Ilmu Komunikasi, Universitas BSI Bandung. Tahun 2015 kukus dari Program Master (S2) di Magister Ilmu Komunikasi, Universitas Budi Luhur Jakarta dengan konsentrasi pada Coorporate Public Relations. Tahun 2016 telah memiliki NIDN dan pada awal tahun 2018 telah mendapatkan Jabatan Fungsional Akademik sebagai Asisten Ahli. 